University of Warwick institutional repository

This paper is made available online in accordance with

publisher policies. Please scroll down to view the document

itself. Please refer to the repository record for this item and our

policy information available from the repository home page for further information.

To see the final version of this paper please visit the publisher's website. Access to the published version may require a subscription.

Author(s: Justin Greaves

Article Title: Biopesticides, Regulatory Innovation and the Regulatory

State

Year of publication: 2009

Link to published version: http://dx.doi.org/10.1177/0952076709103810

Publisher statement: None 


\section{BIOPESTICIDES, REGULATORY INNOVATION AND THE REGULATORY STATE}

Dr Justin Greaves

Department of Politics and International Studies University of Warwick

Coventry

CV4 7AL

J.Greaves@warwick.ac.uk

Tel: 0247657587 


\title{
Biopesticides, Regulatory Innovation and the Regulatory State
}

\begin{abstract}
This article analyses regulatory innovation. It considers, in particular, how a regulatory environmental agency has been encouraged to innovate in the area of biopesticides. The literature on regulatory innovation is reviewed, the discussion situated within Moran's theory of the regulatory state. It considers to what extent innovation has occurred within the agency, looking at its pro-active stance, and how unusually for a regulatory body it has negotiated new policy spaces in which to operate. The article looks at the contextual drivers and also the exogenous and endogenous pressures behind the innovation. It shows how the executive has intervened in order to promote more use of biopesticides and how pressure is also being exerted within the regulatory authority. By using the existing literature and empirical evidence a framework is outlined for explaining the likelihood of regulatory innovation occurring in regulatory agencies.
\end{abstract}

Keywords: Regulatory Innovation, Regulatory State, Regulatory Failure, Regulatory Agency, Biopesticides, Pesticides Safety Directorate (PSD) 


\section{Introduction}

Bureaucrats and regulators are typically risk averse. The desire to avoid things going wrong means they are not natural innovators. Risk averseness does not create an encouraging environment for regulatory innovation (indeed, the term is almost a contradiction). This article uses the example of the Pesticides Safety Directorate's (PSD) work on biopesticides to examine and develop accounts of regulatory innovation. PSD is an agency of the Health and Safety Executive (HSE), employs around 200 scientific, policy and support staff and is responsible for the registration of agricultural pesticides. I They advise Ministers on the development and enforcement of pesticide policy and legislation and also on all aspects of pesticides approvals policy. Applicants for regulatory approval must submit scientific evidence in the form of data packages that follow PSD's guidelines. The data is evaluated by their scientific experts, who in turn prepare reports for consideration by the Advisory Committee on Pesticides (ACP). It then advises Ministers on whether the pesticide should be authorised for sale and use.

The article considers to what extent regulatory innovation has occurred within the agency. Furthermore, how and why has this occurred? To what extent are the characteristics of the agency conducive to regulatory change? The article is based on research interviews, unstructured discussions in informal settings and observations of meetings at PSD. The literature in regulatory innovation is reviewed and based on empirical findings a framework is provided for how innovation may be promoted in other regulatory bodies. At the outset we should stress a methodological point. It is often not appropriate to generalise from a case study to other cases; in other words, they lack external validity. ${ }^{\text {II }}$ It is difficult (perhaps impossible) to identify typical or representative cases; a case study is not a sample of one. The key purpose of this method is not one of generalisation in the usual sense, but whether we can effectively generate theory out of the findings (Yin, 1989). Therefore, we can use the insights of our study to propose a new framework for understanding regulatory innovation in regulatory bodies which could then be tested further in subsequent research.

\section{What are Biopesticides?}

Biopesticides are made up of a broad group of agents. They are defined here, as mass produced, biologically based agents used for the control of plant pests. This definition includes not only the active ingredient of a biopesticide but also the way it is used. ${ }^{\text {III }}$ They can be divided into three sub categories (Copping and Menn, 2000): (1) living organisms (aka natural enemies), which includes invertebrates (eg: predatory insects), nematodes and micro-organisms; (2) naturally occurring substances including plant extracts and semiochemicals (eg: insect pheromones); (3) in some countries - but not the UK - genetically modified plants that express introduced genes that confer protection against pests or diseases (so called plant incorporated products) are also classified as biopesticides. In the UK microbial agents and naturally occurring substances used as plant protection products are regulated by PSD. Non native invertebrates (which include nematodes) included for release in the UK are regulated by Defra under advice from ACRE (Advisory Committee on 
Releases to the Environment). Our main focus is on microbial biopesticides. These tend to be applied inundatively, in a way similar to chemical insecticides, but many exhibit desirable biologically-based properties. (eg: specificity, reproductive potential, low impact on non target organisms, compatibility with other natural enemies, limited toxic residue) (Dent 2000).

\section{Why Such a Low Take-Up?}

Microbial biopesticides have been commercially available for over twenty years, but they 'represent less than $1 \%$ of the global market for agrochemical crop production' (Hajek, 2004, p. 331). Sixty per cent of world sales are derived from commercial preparations based on an entomopathogenic bacterium Bacillus thuringiensis (Lisansky cited in Ehlers, 2007, p 13). Moreover, there are 60 microbial active ingredients available in the USA, compared to EU wide registration for only 6 products (Hokkanen and Menzler-Hokkanen, 2007, p. 4).

There are various reasons why take up has been higher in the USA. There is more institutional support in the form of a dedicated Biopesticides and Pollution Division within the EPA (Environmental Protection Agency). There is also more external policy support through the Interregional Research Project No 4 (IR-4 Project) programme. Generally, however, the take up of biopesticides has been low. One explanation is the 'market failure hypothesis' In other words, the market size is too small to provide economies of scale and encourage firms to enter (see, for example, ACP, 2004, pp. 23/4). Given that biopesticides are niche products with very specific applications, the market size for any one product is small. A single market operates in theory within the European Union (EU) where the existing regulatory arrangements can be described as 'a dual-system where the Community evaluates active substances and Member States evaluate and authorise products containing them' (European Commission, 2001, p. 2). The Commission accepts, however, that mutual recognition between member states does not work well. Directive 91/414, dealing with such issues, is currently under revision and could create a larger market for biopesticides and overcome some of the economies of scale problems.

Whilst market failure plays its part, an alternative hypothesis (and the one we are concerned with here) is that of regulatory failure. Systems of regulation can have unintended consequences. Bureaucratic theory points to a tendency for mechanisms to displace goals, for processes to become more important than outcomes (Merton, 1968). There may be consideration of policy instruments in isolation from their wider effects and rules may be applied too rigidly. This is not a specific failure by regulators themselves in terms of how they have carried out their jobs. Rather we are referring to systemic problems arising in regulation, along with specific problems in the regulation of biopesticides. The UK regulatory system was developed according to a chemical pesticides model, and this may have acted as a barrier to biopesticide commercialisation (Advisory Committee on Pesticides, 2004). Registration fees for biologicals (whilst lower than for chemicals) appeared substantial given UK market potential and the turnover of a typical R \& D micro-business (Pendlington and Dickinson, 2003). Companies were also deterred because of the costs of gathering the 
amount of supporting data that thought they would be required to produce (Pendlington and Dickinson, ibid). In short, the system did not facilitate the efficient registration of biological alternatives. As Waage has stated, 'biopesticide development is locked into an inflexible and unimaginative chemical pesticide model. In this position, all of the shortcomings of biopesticides relative to chemicals emerge and none of the benefits' (Waage, 1997, p. 14). Waage adds:

It is not the industry alone, but the entire pesticide regulatory process which has not adapted itself to the new opportunities which biopesticides provide. In their emphasis on high efficacy standards typical of fast-acting potent chemical products, registration procedures make little allowance for new products whose effect is a combination of direct kill and the conservation of natural enemies' (1997, p.16).

To put it another way, there was a potential government failure as the entry costs to the market are raised by an onerous registration process designed for chemical pesticides (Grant, 2005). The regulatory system needed reform: hence the topic under discussion.

\section{What is Regulatory Innovation?}

Models of the regulatory state provide a framework to our discussion. Moran's work is of particular importance here, in terms of developing a model of its essential characteristics (2000; 2002; 2003; 2005). New executive agencies are contracted to deliver policy; a newly privatized sector is subject to a network of specialized regulatory agencies; and government has turned to the specialized regulatory agencies to control large areas of economic and social life (Moran, 2005, p. 156).

The main link, however, is with the literature on regulatory innovation. Innovation can be seen as 'the application of new solutions to old problems, or new solutions to new (or newly constructed) problems, but not old solutions to old problems' (Black, 2005a, p. 9). This is illuminated by Hall's (1993) typology of policy change. First order changes are changes to the levels or settings of basic instruments (not considered here as innovations). Second-order policy changes involve changes in technique, process or instrument, but not in the overall goals of policy or understanding on which it is based. Third-order changes involve changes in the goals of policy and understandings on which the policy is based, along with second and first-order changes. Third-order changes are 'paradigm shifts', changes in the terms of a policy discourse: the understandings on which it is based and the goals pursued (Kuhn 1962).

This paper, like Black, views regulatory innovation as innovation in any aspect of the regulatory system or regulatory regime (Black, 2005a). A regulatory regime is the set of interrelated units engaged in joint problem solving to address a particular goal, its boundaries being defined by the definition of the problem being addressed, and it has a degree of continuity over time (Hood et al, 2001). This is a wider definition of regulatory innovation than that of Sparrow (innovation in modes 
of risk regulation: Sparrow 2000) or Moran (innovation in institutional arrangements: Moran 2003). The advantage, however, of using the notion of a regulatory system or regime is that it draws attention to both to the range of participants in the system and their interrelationship (Black, 2005a). Therefore, regulatory innovation consists of innovation in the performance of regulatory functions, institutional structures and organizational processes in the regulatory regime (Black, 2005a).

Given that existing actors in the policy network are primarily orientated towards chemical solutions, how can change be brought about? Policy network theory suggests that networks are good at managing incremental change, but tend only to innovate in conditions of crisis or exogenous shock. This is complicated by the fact that the EU has the leading role in pesticides legislation. Its system of decision making and inbuilt 'checks and balances' does not promote rapid policy change or paradigm shifts. For defenders of the status quo, 'a sectoral policy network which has a high degree of cohesion among its members is a very powerful political resources' (Daubjerg, 1998, p. 79). As Stringer and Richardson put it, 'the objective of the policy-making process within these communities is often not the solving of real problems but the management of the avoidance of conflict, the creation or maintenance of stable relationships, and the avoidance of abrupt policy changes' (1982, p. 22). Using the insights of the regulatory innovation literature along with interviews we can seek to identify agents and processes that create the conditions under which regulatory innovation can occur.

\section{How and Why Does Regulatory Innovation Occur?}

The more difficult question is how and why does regulatory innovation occur? The literature which specifically refers to innovation is quite narrow. Nevertheless, Black divides up the explanations and theories into five 'worlds': the worlds of the individual, the organization, the state, the global polity and the innovation (Black, 2005b). In the first world the individual is both the site and agent of innovation. An emphasis on champions is found in much of the work in public sector innovation. The role of the 'champion', a charismatic individual who backs the innovation, is also emphasised in studies of innovation within firms. The characteristics of such champions are risk preferring, being open to new ideas, persuasive, empathetic and occupying key strategic positions within organizations. Generally speaking, such individuals will have sufficient financial resources to absorb losses from unprofitable innovations, be able to cope with a high degree of uncertainty, and have a favourable attitude towards change and risk-taking. In the world of the individual, therefore, innovation is explained by one, or sometimes two, key individuals who are able to push their performed innovation through critical decision junctures or 'policy' windows. This relates to the work of Kingdon (1984) who argued that 'policy entrepreneurs' take advantage of policy windows offered by the concatenation of policy problems, policies and politics to catapult new items onto the political agenda and change policy.

The organizational world concentrates on innovations within organizations, traditionally profit-making organizations, but increasingly non-profit public and 
private sector organizations. Innovation is fostered by organizations where the leader or leaders have a positive attitude towards change, which have low centralization, where its members have a high degree of knowledge and expertise, in which procedures are not highly formalized, where there is a high degree of interpersonal connections between the organization's members, and a high degree of organizational slack, for example, the extent to which uncommitted resources are available to the organization, with the biggest factor being size: ceteris paribus, large organizations are more innovative than smaller ones (Rogers, 2003; Mahler and Rogers, 1999). Also important are the existence of cultures which are supportive of risk-taking and can tolerate mistakes and failures.

The 'state world' focuses on government, either taken as an aggregate, or a particular unit of government (a local authority, or NHS trust, or a regulatory agency). The work on innovation within government comes mainly, as expected, from political science. As Black writes, "if the question "how and why does innovation in public policy occur" is rephrased as "how and why does policy change occur" or "how and why does policy learning occur", then immediately almost any theory of public policy formation would have an answer' (Black, 2005b, p. 25). Public choice theory, for example, would state that innovations are political goods which are sold to the highest bidder or coalition of bidders, and will depend on the distribution of costs and benefits of particular groups. Pluralism would argue that they come about through an interplay of interest group pressures. Public Opinion response theory would state that they are the result of public pressure, mediated by the media. Rational theories of bureaucracy would argue that they are the result of self-interested bureaucratic decisions (Downs, 1967).

None of these state models, however, allow for the expectation that 'ministers decide' or at least express a policy preference. Furthermore, there is not always such a distinction between change and innovation in the literature as Black suggests (Downs, 1967, seems to use the terms interchangeably). That being said, the literature in the state world directly associated with 'innovation' is rather narrow, and in its casual explanations does not provide a particularly rich seam of analysis (Black, 2005b). The institutional literature, however, has focused to some extent on innovations, and provides a broader set of arguments. Central to 'new institutionalism', for example, is that 'institutions matter' when it comes to individual and social action and interaction as they provide the structure to which the action and interaction occurs (March and Olsen, 1984). Such an approach suggests that innovation is explained by the impact of institutional structures on decision making by political actors, including bureaucrats and those in regulatory agencies. The form that regulatory innovations take in different regulatory regimes will depend upon the extent to which they 'fit' with the surrounding institutional environment.

The site of analysis of the 'global world' is policy-making by international bodies and networks. States have been relatively passive or bypassed in many areas of policy development which are nonetheless regulatory in character. Either they are willing to be instructed by international organizations or epistemic communities as to what action to take ${ }^{\text {IV }}$, or they are bypassed by transnational organizations which set 
technical or professional standards (Boli and Thomas, 1997). In the 'world of the individual' an idea is likely to be adopted and enacted primarily on the shape and form of the innovation itself, and for some, on the extent to which it 'fits' with the prevailing cognitive/normative frameworks. 'The more the innovation is simply expressed, trialable and observable, the more it is expressed as a general theory, and the more it fits, or can be represented as fitting, with dominant cognitive and normative schemas, the more likely it is the idea or innovation will be adopted' (Black, 2005b, p. 40).

The five worlds are not mutually exclusive and do not exhaust the possible range of explanations that may exist. Black can be criticised for trying to cover every possible theory or explanation: there is not much differentiation or selection, and therefore potentially little leverage. To some extent she acknowledges this, stating 'one is inevitably prey to the criticism that what is offered is simply a bewildering variety of perspectives or explanations with no clear direction as to which course one should take' (Black, 2005b, p. 41). Black states that her aim is to 'provide an analytical framework for much richer explorations’ (Black, 2005b, p. 41). Academia has been criticised for its lack of high quality research on innovation in the public sector, particularly of the 'how was it done' kind (Cabinet Office, 2003). Black's 'five worlds' do not seem to lend themselves to the practice of regulatory innovation. The world of the individual and some of the structural and procedural aspects of the organizational may provide identifiable tools for action. It is less easy to translate the 'organizational environment' or 'institutional structures' into such tools. The case studies in Black's edited volume, moreover, show the contingency of many accounts of regulatory innovation. It is concluded that 'neither the occurrence nor the outcomes of innovation can be controlled and predicted'. 'Innovation simply cannot be engineered' (Black and Lodge., 2005, p 194). This article's stance is that whilst it may often come about by chance, agents and processes can be identified which are likely to increase the chance of it occurring. Moreover, in this particular case a consideration of the contextual and exogenous and endogenous drivers (whilst overlapping with Black’s analysis) may provide a slightly better framework.

\section{Regulatory Innovation within PSD}

In June 2003 PSD launched a pilot scheme to encourage the development and introduction of alternative control measures. Reduced registration fees were set for the purposes of the scheme. PSD also held pre-submission meetings to encourage and assist applications for alternative control products. The aim was to increase the availability of biological pesticides in the UK by improving knowledge and raising awareness of PSD requirements and how to meet them.

In April 2006 the agency announced the introduction of a permanent Biopesticide scheme to facilitate more alternative products to enter the market. The key elements of the scheme are:

- The appointment of a biopesticide champion to provide initial contact for product innovators/manufacturers, and help them through the approval 
process. Their role is also to provide a voice within PSD where issues may affect biopesticides.

- Appointment of 'Biocontacts' in each of the specialist areas of risk assessment to provide guidance on specific scientific and regulatory issues.

- Encouraging potential applicants to meet with PSD at the earliest possible stages of product development.

- The provision of specific guidance to applicants (via free pre-submission meetings) flagging up possible hurdles to address and identifying the best way forward for their product.

- The provision of more accessible information on the regulatory process with a new Biopesticide area on their website.

- A fee for evaluations approximately a quarter of the cost of a conventional pesticide.

The functions of the scheme can be summarised as follows. Firstly, they seek to reassure developers of new products that the regulator is receptive to products other than synthetic pesticides. Secondly, they seek to facilitate the successful completion of the regulatory process by providing advice and assistance on requirements. Thirdly, they seek to reduce the cost of regulation by setting fees at a lower level. Prior to the introduction of the scheme, three actives and four products had been approved between 1985 and 1997. V Since the introduction of the pilot scheme, five biopesticide products have been guided through the system and approved for use in the UK. Five other products are at various stages of evaluation and a large number of companies are discussing possible applications (PSD, 2007, p. 19). ${ }^{\mathrm{VI}}$ PSD were told by the biopesticide industry that if they reformed the 'floodgates would open' - that there were a large number of products waiting to be registered. Whilst this has not happened outcomes have been favourable compared to the preceding period. The organization has undergone an internal reorientation in seeking to proactively facilitate biopesticides registrations. They stress their 'pragmatism' and that the rules are 'open to interpretation'. An example is the encouragement of the use of published data instead of requiring expensive and lengthy field trials where appropriate in the approvals process. They acknowledge the need to innovate and have familiarized themselves with the fact that different questions have to be asked about biological products, and that questions that may be important for synthetics are not necessarily relevant for biologicals.

Does, however, this change count as innovation? To return to Hall's typology, some aspects of the biopesticides scheme may count as first order policy changes (eg: lower fees for biologicals). Most, however, fall comfortably within the category of second order policy changes (eg: a biopesticides champion, pre-submission meetings etc). In some ways lower fees are the biggest change but, as Black suggests, first order changes may be significant in terms of scale or impact whilst not strictly counting as innovation (Black, 2005a). One hypothesis is that we are moving away from a (chemical) pesticides paradigm to an ecological pest management paradigm if so, it may even be appropriate to talk of third order policy changes. ${ }^{\mathrm{VII}}$ It is important to consider the scheme as a whole - it is the broader point that is of more interest rather than trying to map on to the minutiae of the scheme. We should, 
however, distinguish formal aspects of the scheme (eg: reduced fees) from what has come about as a result of the scheme (eg: PSD stressing their more pragmatic stance). Taking everything together, we can describe what has occurred as regulatory innovation. To return to Black, it has involved 'new solutions' (Black, 2005a). It is an unusual step for a regulatory agency which usually has to stick closely to what is laid down in statute to negotiate new policy spaces in which to operate (which is effectively what has happened here). PSD sought clearance from Defra, particularly in relation to the funding of the scheme (a point we return to below), thereby creating a new space in which to take action. Arguably, this has extended their formal remit, albeit cleared by ministers. As Richard Davis, their Director of Approvals puts it, this has been 'quite remarkable for a regulatory agency' (Sainsbury's Conference, $18^{\text {th }}$ March 2008). VIII There is a view within PSD that the capacity for regulatory innovation is limited as legislation would often be needed and that, particularly at the European level, it is a protracted process over which PSD has little influence. ${ }^{\mathrm{IX}}$. A degree of regulatory innovation has successfully occurred, however, and continues to be developed on the basis of experience.

\section{Contextual Drivers}

It is helpful to look at the contextual drivers. In the chapter 'The Background and the Need for Change' (www.pesticides.gov.uk/garden.asp?id=1523, accessed $12^{\text {th }}$ March, 2007), from the document 'A Draft National Strategy for the Sustainable Use of Plant Protection Products', PSD talk of various drivers for change in the ways in which plant protection products are regulated and used and some of these are relevant to our discussion.

Firstly, the public are concerned about the possible health effects of pesticide residues on food. Pesticide residues are regulated in the EU by Maximum Residue Levels (MRLs) which provide substantial margins of safety to deal with a worst case scenario. Nevertheless, many Non Governmental Organizations (NGOs) point to what they see as the harmful effects of pesticides on human health (picked up in popular literature by authors such as Humphreys, 2001). Secondly, there is consumer preference, even when there are no safety concerns, for a reduction in pesticide residues in food, leading to action by retailers, consumers and the Food Standards Agency. From a food policy perspective, pesticide residues on fresh foods are a concern as they may deter consumers from eating fruit and vegetables which are thought to be desirable in terms of preventive health (biopesticides are much less likely to have such residue problems) Retailers often push for levels of pesticide reduction more rigorous than those required by regulators, which in themselves are very stringent. There is also a requirement to integrate chemical pesticides with alternative methods in order to develop systems of crop protection which are sustainable. This has an ecological dimension; crops need to be protected using methods which do not damage the environment, in particular in terms of water pollution and biodiversity. Public concern over the impact of pesticides on the environment, therefore, is a third driver of change. Broad spectrum synthetic pesticides can reduce populations of beneficial, naturally occurring predators and 
parasitoids (that being said, generations are now available which have a narrow spectrum of activity and good environmental characteristics).

Pesticides are also required which prevent the development of resistance by the pest to the control agent. Following the implementation of European Directive 91/414/EEC there has been a significant decline in the number of active ingredients permitted for use in crop protection products. Moreover, because of the expense of research and registration, manufacturers are unlikely to develop new chemical products on a large scale. These are further drivers of change. As there has been a reduction in the number of pesticide products available for use, this increases the problem of pesticide resistance. When an effective pesticide is applied to a crop and the majority of the pest population dies 'sometimes a few individuals remain that are physiologically different and can tolerate the pesticide. The "new strain" of the pest that has been created is resistant to the pesticide and the population can then increase even when the pesticide is re-applied' (Hajek, 2004). The broad solution is to use IPM. 'There is a role for chemical pesticides in IPM when infestations cannot be controlled by any other means, but they should be used as a last rather than as a first resort. There is also scope for increased use of alternatives to chemical pesticides such as biological controls and in particular biopesticides' (Grant, 2005, p. 10).

\section{Proximate Drivers: Exogenous and Endogenous Pressures}

We can now move onto the proximate drivers, and within this separate out analytically the exogenous and endogenous pressures for change. The intervention of the executive is an example of the former. Defra has been keen to encourage the wider use of biopesticides (in order to achieve sustainability objectives). ${ }^{\mathrm{X}}$ Given the slow progress being made, the institutions of the core executive needed to intervene in the policy-making process. The then Business Regulation Team (BRT) of the Regulatory Impact Unit of the Cabinet Office discovered in 2002 that, 'although Defra had been funding the research and development of 'alternatives' to synthetic pesticides, none had been able to obtain the authorisation required for such products to be placed for sale in the UK as plant protection products'. They observed that PSD's testing requirements 'were evidently designed to cope with standard, mass- produced synthetic chemical pesticides which, by their nature, tend to deliver very high efficacy rates, and not with this group of safer alternatives.....this appeared to be an interesting example of regulation-inspired market failure' (Business Regulation Team, 2003, p. 19).

In the coded language of the civil service, 'the BRT approached PSD in order to seek a solution to the problem'. In Grant's words, 'they used their authority to lean on PSD' (Grant, 2005, p. 15). The fact that the Government leaned on PSD was confirmed both by a senior figure within PSD and by an industrial executive seconded to BRT to work on biopesticides. Richard Davis, commented that 'there was a political driver but it wasn't Defra or growers, it was the Cabinet Office'. Furthermore, 'it was someone on secondment to the Cabinet Office, not a career civil servant' (Biopesticides Workshop, $31^{\text {st }}$ October 2007). ${ }^{\mathrm{XI}}$ As Davis suggests, 'we did 
need some pressure to introduce the scheme. He gave us a kick in the teeth' (REBECA Conference, Sept 20/21 2007). ${ }^{\text {XII }}$ PSD’s ‘aims and objectives', agreed with ministers in spring 2003, included reducing the 'negative impact of pesticides by encouraging reductions in their use, taking account of good practice, and developing and introducing alternative control measures' (PSD, 2004, p 9). Pressure from the Cabinet Office has worked alongside an endogenous steer from within PSD. They were keen to discuss how the new aim could be promoted (Business Regulation Team, 2003). As Davis put it, as a 'typical regulator' they took a stand but 'bowed' to government pressure, accepting that change was necessary (Biopesticides workshop, $31^{\text {st }}$ October 2007). The Director of Policy and the Director of Approvals made the joint decision to have a pilot scheme. Defra provided money to allow reduced fees for biopesticides but only on a temporary basis. The Director of Approvals decided to make the Biopesticides Scheme permanent; thereby confirming that key individuals were vital in moving the process forward.

Not all aspects of PSD necessarily promote innovation. One grower, for example, put it that the agency has an attitude of 'we would like to do that, but we can't. (They) are civil servants that regulate, they cover their backs' (interview, $25^{\text {th }}$ May, 2005). A senior PSD official, meanwhile, commented that there is 'a danger in any technical body that that it follows an almost separate set of objectives or a more limited set of objectives. Not saying "What does the Minister want"? "What would be politically acceptable'? "How is it going to look in the Sun"? (interview, $28^{\text {th }}$ November 2007). To put it another way, a technical body may be more resistant to the political pressures which can help push through change. A respondent from a stakeholder organization suggested that PSD are a 'technical regulator', as opposed to a more political regulator like the Environment Agency. He added that 'technical regulators have to be a lot more old school. There is an administrative culture there (at $P S D$ ) and it doesn't look dynamic....PSD have to have a technical dialogue with people with a technical bent'. However, whilst it does 'not have a very glossy public persona (they) can be innovative when they are allowed to be' (meeting, $7^{\text {th }}$ October, 2005).

A respondent from an environmental group pointed to 'big flaws in ways in which they work and operate...part of the problem is the bureaucracy involved. They take a policy steer from Defra, there's a time lag on it, and lots of inertia... they follow the recipe, but who's checking the recipe to make sure it's the right one? (interview, $26^{\text {th }}$ October, 2005). Our interviews and observations, however, reveal that Defra has a fairly 'hands off' relationship with PSD. This is in part due to them being an 'executive agency' as opposed to part of the traditional civil service. Defra are also aware that pesticide issues are highly technical and this lack of knowledge may make them wary of intervening. They may also prefer to keep themselves distant, so that if anything goes wrong PSD will take the flak. XIII The minister responsible for pesticides policy, Phil Woolas, commented at an open meeting of the ACP that, 'It's an area of public service if it gets in the news, it tends to be negative. As an elected politician one wants to keep it out of the news. It is not an easy area of government policy' $\left(12^{\text {th }}\right.$ November, 2007). Exogenous pressure from government, therefore, 
promotes regulatory innovation, but relative autonomy from Defra (perhaps reinforced by PSD's location in York) provides space for it to occur. This decentralisation from their political masters explains how whilst government needed to provide an initial exogenous shock to promote alternatives, innovation has been sustained within the agency.

It is also important to look at how work is allocated. We observed the approvals process being started by three resource managers with an initiation meeting. This, alongside the fact that the approval process has to integrate a number of different specialisms (a large number of individuals were brought into pre-submission meetings), shows that it is a relatively horizontal process. This, in comparison to a vertical structure, is more favourable to innovation as individuals have an opportunity to 'bounce ideas' off their colleagues and learn from different specialists. Richard Davis has stressed the importance of an effective and strong team in driving through change (Biopesticides workshop, $31^{\text {st }}$ October 2007). Certainly, those working on biopesticides have shown great enthusiasm for their work, perhaps because of a desire to do a 'better job', or gain skills or expertise, or doing the job well is a successful career building strategy (see Downs, 1967). A senior official commented that they were 'lucky in the people they had picked to work on biopesticides, if others had been chosen it may not have worked so well' (unstructured discussion, October $31^{\text {st }}$ 2007). Those within approvals also see themselves as scientists first and as regulators second: or, in other words, 'scientific regulators'. They are keen to extend their scientific expertise and have shown an interest in learning about biological alternatives (eg: through REBECCA ${ }^{\mathrm{XIV}}$ ). This knowledge is driving regulatory innovation forward (linking back to Black, 2005b, p. 20), with pre-submission meeting in particular allowing PSD to build up their expertise and develop a more appropriate registration process. As Davis puts it, 'they have built a team of specialists who understand the issues and are continuing to learn' (Sainsbury's Conference, $18^{\text {th }}$ March 2008).

There is a difference between Downs (1967), who argues that change is easier to drive through in smaller organizations (the more individuals affected the more difficult it will be to push it through), and some of the literature on organizations that suggests it is easier in larger organizations (due to uncommitted resources and organizational slack) (eg: Rogers, 2003; Mahr and Rogers, 1999). Organizational slack in larger bureaucracies could lead to projects which take up a lot of time but do not get very far. Moreover, staff may be more 'accountable' for their actions in smaller organizations; in other words it is easier to see who is performing their jobs well. Effective working relationships and a high degree of interpersonal connections exist within the approvals side of PSD (linking back to Black, 2005b, p.20); its 'closeknit' nature fostered by its size. On balance, therefore, the relatively small size of the organization and its clear purpose are likely to be conducive to regulatory innovation. PSD was also set up, on the approvals side, as a fee generator agency (in other words, there are commercial elements to the agency). As they have to cover their costs (at least in part) through registration fees they are different to many government bureaucracies. ${ }^{\mathrm{XV}}$ These financial pressures may make the organization more flexible and innovative: after all, there are consequences if they do not succeed in gaining an 
adequate income. Given, however, that they have to cover their costs there are limits to how far they can go in terms of lower registration fees. As a senior official within PSD put it, 'Biopesticides run counter to what the agency needs which is more money in from pesticides' (interview, $28^{\text {th }}$ November 2007). Commercial pressures in this instance, therefore, may not be helping the promotion of alternatives.

\section{A ‘Champion’ Organization?}

We have seen how the literature refers to 'champions' who push through innovations (Black, 2005, pp. 17-19). The role of the (part-time) Biopesticides Champion within PSD is to assist biologicals through the registration process, rather than be a champion in the stronger sense of the word. There is, moreover, a gap in the literature when it comes to 'champion organizations'. One argument is that an organization, preferably quasi-governmental in character and acting as an advocate for biopesticides, would lead (and have led) to greater regulatory change. EPA, as noted earlier, has a dedicated Biopesticides and Pollution Prevention Division (BPPD) taking on an advocacy role. The size of the US domestic market offers a lot of opportunities for biopesticides; a dedicated unit in the UK may have insufficient work to do.

How would an advocacy role, moreover, fit into the overall role of PSD? Its website states that 'the aim of PSD is to protect the health of human beings, creatures and plants, safeguard the environment and secure safe, efficient and humane methods of pest control, by controlling the sale, supply, storage, advertisement and use of pesticides' (http://www.pesticides.gov.uk/corporate.asp?id=232, accessed 9/10/07). As part of the strategy for sustainable food and farming, meanwhile, it is tasked with reducing negative impacts of pesticides on the environment. It could approach this task by promoting the wider use of biopesticides but this would require ministerial guidance. The approvals side of PSD, moreover, is set up to undertake the task of registration to ensure the safe use of pesticides. It is debatable whether it is equipped to take on an advocacy role. As Richard Davis put it, 'my challenge is to promote the scheme, not to promote biopesticides, there is a difference' (Biopesticides workshop, $21^{\text {st }}$ October 2007). Another option would be for an organization such as Natural England (http://www.naturalengland.org.uk) to become a champion. When asked if they could act as an advocate, however, they responded that it couldn't be 'a categorical decision that they're better, they are not always better. Historical data base shows that some biological control mechanisms can create environmental problems'. Without a champion organization, however, the case for biopesticides risks being sidelined.

\section{Reform of Institutional Structures}

As a new institutionalist would claim, the structure of institutions shapes how people act within them. The UK Royal Commission on Environmental Protection (RCEP) report on Crop Spraying and the Health of Residents and Bystanders (2005) recommended that responsibility for pesticides policy be separate from that of the approval of pesticides. One suggestion was to move the policy function from the PSD to a unit within the Environment Directorate of Defra. The Report adds that the 
remaining functions concerned with the approval of pesticides could be transferred to the Environment Agency. This could change the focus of PSD's work to environmental impact which may be even more costly than demonstrating efficacy. The transfer of policy functions to Defra, meanwhile (making it more of a technical regulator), could make PSD less amenable to change. ACP's response (2005) to the RCEP Report stated:

We ....... emphasise the need, when making decisions in this area, to take into account the current excellence of the scientific and technical staff at PSD. In our view, their performance is as strong as that of the best government departments and agencies, and ahead of the majority. It also compares favourably with that of pesticide regulatory agencies in other European countries. We believe it would be most unfortunate if a reorganization caused this valuable concentration of expertise to be lost (ACP, 2005, p. 33).

The Hampton Review on UK regulation set up by the Chancellor of the Exchequer, reported in April 2005, and proposed streamlining the regulatory structure on the grounds that there were too many small regulators. Whilst the report did not make a specific recommendation regarding PSD, which was on the cusp as far as size was concerned, the implication could be drawn that it should be merged into a larger more thematic regulator. Defra, therefore, launched a formal consultation on merging PSD with the Health and Safety Executive (HSE), linking to the latter's existing responsibilities for biocides and REACH. XVI Following this, Ministers decided the organizations should be merged from 1 April 2008. The merger may lead to a greater emphasis on bystander and worker protection issues, making it even more difficult to secure the timely registration of innovative products that serve sustainability objectives. There is also a risk that a greater focus on chemicals strategy within the merged organization might lead to less attention being placed on biological alternatives. It is noticeable, for example, that biopesticides were not mentioned in the proposition for the merger. Despite the thinking behind Hampton, a relatively small organization may be more flexible and responsive. It may be better able to develop an organizational culture favouring innovative responses to new challenges. Furthermore, a body with a clear and specific purpose may be more conducive to regulatory innovation than a larger and potentially more unwieldy one.

\section{Conclusions}

Regulatory innovation has successfully occurred in the area of biopesticides. A chemically driven regulatory model has been replaced by a modified model more adapted to the specific needs of biological control agents, leading to a partial resolution of 'regulatory failure' problems. In terms of Black's five worlds', key individuals have been vital in driving the process forward, both within the Cabinet Office and PSD. Similarly, organizational characteristics have played a role (eg: the horizontal distribution of work, the desire for knowledge, interpersonal connections etc). Moreover, the intervention of the Cabinet Office ('the state world') along with the impact of institutions should not be understated. Although the 'global world' is less significant, PSD operates within OECD guidelines, has engaged with REBECA, 
and the review of 91/144 is potentially important. In terms of the 'world of the innovation', biopesticides fit into their surrounding environment, not least in terms of issues surrounding sustainability, pesticide resistance and the limited number of products. They are not, however, an 'idea' easy to get to grips with or widely understood.

Black's worlds provide an interesting starting point. Similarly, regulatory innovation can be explained through a consideration of the contextual and proximate drivers, and exogenous and endogenous pressures. We need, however, a more detailed framework for understanding innovation in a regulatory agency. The purpose is not to contradict or refute Black's analysis but to develop and expand it. Black's framework is broad enough to account for most instances of regulatory innovation (some may argue it is too vague), but we should be more specific when looking at a particular area. Based on our research a framework or model is proposed whereby the likelihood of regulatory innovation occurring in a regulatory agency, all things being equal, is increased by:

- Exogenous pressure from central government.

- Key individuals within the organization being prepared to drive through change.

- Political as opposed to technical regulators.

- A degree of autonomy from government providing space for innovation to occur.

- A horizontal distribution of work.

- Selecting the right individuals to work on innovative projects.

- Regulators keen to learn and develop their expertise (in particular scientific regulators).

- Small organizations (with a clearly defined purpose).

- Commercial or financial pressures.

- An organizational champion or advocate.

As stated at the outset there are difficulties in generalising our findings.

Nevertheless, the framework proposed can be applied more widely as an analytical tool. Research of other regulatory agencies, moreover, could help strengthen the external validity of the framework. Regulatory innovation in biopesticides regulation is not helped by the relatively weak policy network. The industry is (economically) weak, largely consists of Small and Medium Sized Enterprises (SMEs), is still undergoing organizational development, and does not have the policy resources of the agrochemical industry. Environmental groups are often fairly isolated from the debate and the IBMA (International Biocontrol Manufacturers Association), whilst developing in terms of organizational effectiveness, often lacks the resources to carry out its role. The drivers for change have tended not to be growers, retailers or manufacturers. Similarly, whilst the public may be concerned about pesticide residues they are not well informed on biological alternatives (and may be put off by the term 'biopesticides'). Further research would be helpful on public opinion, perhaps through the use of focus groups or citizen's juries. Biopesticides tend also not to have a high profile among political decision makers. Any framework for understanding the 
potential for regulatory innovation in a regulatory agency, therefore, should also take account of:

- how developed the policy networks are in the particular area.

- how salient the issue is among the public.

- how high a profile the issue has amongst politicians.

In terms of the regulatory state model the priority given to regulation sets up expectations of innovation and responsiveness to societal demands which can be hard to meet in practice. In relation to regulatory innovation frameworks there is a fundamental tension between expectations that regulators will be consistent, predictable and impartial, and yet also innovative. The consequences of making a mistake are serious, especially where public safety/environmental protection is involved, but regulators also have to respond to changing demands in society. Regulatory innovation is important, moreover, if regulators are to retain the trust of politicians and stakeholders. This paper offers an example of successful regulatory innovation in practice. It has required a government steer, appropriate contextual circumstances, and a positive response from the agency based upon suitable individuals and the right organizational and institutional characteristics. 


\section{Acknowledgments}

I would like to thank Wyn Grant, David Chandler, Mark Tatchell and David Buffin for comments on this article and earlier drafts.

The research project upon which this article draws is funded by the Rural Economy and Land Use Programme (http://www.relu.ac.uk). 


\section{References}

Advisory Committee on Pesticides (2004), Final Report of the sub-group of the Advisory Committee on Pesticides on: Alternatives to conventional pest control techniques in the UK: A scoping study of the potential for their wider use.

Advisory Committee on Pesticides (2005), Crop Spraying and the Health of Residents and Bystanders: a Commentary on the Report. Published by the Royal Commission on Environmental Pollution in September 2005 (available at http://www.pesticides.gov.uk/acp_home.asp).

Black, J. (2005a), What is Regulatory Innovation, in Black, J., Lodge, M., and Thatcher, M. (eds), Regulatory Innovation, pp.1-15, (Cheltenham UK: Edward Elgar).

Black, J. (2005b), Tomorrow’s World: Frameworks for Understanding Regulatory Innovation. In Black, J., Lodge, M., and Thatcher, M. (eds.) Regulatory Innovation, pp.16-44, (Cheltenham UK: Edward Elgar).

Black, J., and Lodge, M. (2005), Conclusions. In Black, J., Lodge, M., and Thatcher, M. (eds) Regulatory Innovation, pp. 181-197, (Cheltenham UK: Edward Elgar).

Boli, J., and Thomas, G.M. (1997), 'World Culture in the world polity: a century of international non-governmental organization’, American Sociological Review, 62 (2), pp. 171-190.

Business Regulation Team (2003), Regulatory Impact Unit: 2003 Report, (London: Cabinet Office).

Cabinet Office (2003), Innovation in the Public Sector, (London: HMSO).

Copping, L.G., and Menn, J. J. (2000), 'Biopesticides; a review of their action, applications and efficacy’, Pest Management Science, 56, pp. 651-676.

Daugbjerg, C. (1998), Similar Problems, Different Policies: Policy Networks and Environmental Policy. In Marsh, D. (eds.) Comparing Policy Networks, pp. 75-89, (Buckingham: Open University Press).

Dent, D. (2000), Insect Pest Management, (Wallingford UK: CABI Publishing).

Downs, A. (1967), Inside Bureaucracy, (Boston. Little, Brown and Company).

Ehlers, R. (2007), Perspectives for Safer Plant Protection, presented at the REBECA Conference: Balanced Regulation for Biological Plant Protection Products, Brussels 20-21 Sept 2007 (available at http://www.rebecanet.de/downloads/Brussels\%20conference/Brussels\%20Ralf-Udo\%20Ehlers.pdf) 
European Commission, (2001), Report from the Commission to the European Parliament and Council: Evaluation of the Active substances of plant protection products, Brussels: COM(2001) 444 final.

Flyvjerg, B. (2006), 'Five misunderstandings about case-study research', Qualitative Inquiry, Vol 12, pp. 219-245.

Grant, W. (2005), The challenges of interdisciplinary environmental research: the case of Biopesticides, an article presented at the Northeastern Political Science Association Conference, Philadelphia.

Hajek, N. (2004), Natural Enemies: An Introduction to Biological Control, (Cambridge: Cambridge University Press).

Hall, P. A. (1993), 'Policy paradigms, social learning, and the state: the case of economic policymaking in Britain’, Comparative Politics, 25 (3), pp. 275-96.

Hampton, P. (2005), Reducing Administrative Burdens: Effective Inspection and Enforcement, (London: HMT).

Hokkanen,, H., and Menzler-Hokkanen, I. (2007), Trade off effects of current regulatory practice, paper presented at the REBECA Conference: Balanced Regulation for Biological Plant Protection Products, Brussels 20-21 Sept 2007 (available at http://www.rebecanet.de/downloads/Brussels\%20conference/Brussels\%20Heikki\%20Hokkanen.pdf).

Hood, C., Rothstein, H., and Baldwin, R. (2001), The Government of Risk: Understanding Risk Regulatory Regimes, (Oxford: Oxford University Press).

Humphrys, J. (2001), The Great Food Gamble, (London: Hodder and Stoughton).

Kingdon, J. W. (1984), Agendas, Alternatives and Public Policies, (Boston: Little Brown).

Kuhn, T. (1962), The Structure of Scientific Revolutions (Chicago: Chicago University Press).

Mahler, A., and Rogers, E.M. (1999), 'The diffusion of interactive communications and the critical mass: the adoption of telecommunications strategy by German banks', Telecommunications Polity, 23, pp. 719-740.

March, J.G.,b and Olsen, J.P. (1984), 'The new institutionalism: organizational factors in political life’, American Political Science Review, Vol 78, pp. 734-49.

Merton, R.K. (1968), Social Theory and Social Structure, (New York: The Free Press). 
Moran, M. (2000), 'From command state to regulatory state', Public Policy and Administration, Vol 15, No 4, pp. 1-13.

Moran, M. (2002), 'Review article: understanding the regulatory state', British Journal of Political Science, 32, pp. 391-413.

Moran, M. (2003), The British Regulatory State: High Modernism and HyperInnovation, (Oxford: Oxford University Press).

Moran, M. (2005), Politics and Governance in the UK, (Basingstoke: Palgrave Macmillan).

Pendlington, D., and Dickinson, S. (2003), 'New support for biopesticides in the UK, Pesticides News, No 61, Sept 2003, pages 22-23.

Pesticides Safety Directorate (2004), Pesticides Safety Directorate Annual Report and Accounts 2003/04, (London: the Stationary Office) (available at http://www.pesticides.gov.uk/uploadedfiles/Web_Assets/PSD/PSD_Annual_Report_2 003-4.pdf

Pesticides Safety Directorate, (2007), Pesticides Safety Directorate Annual Report and Accounts 2006/07, (London: the Stationary Office) (available at http://www.pesticides.gov.uk/uploadedfiles/Web_Assets/PSD/ARA\%202006-07.pdf)

Rogers, E.M. (2003), Diffusion of Innovations, $5^{\text {th }}$ Edition, (New York: Free Press).

Royal Commission on Environmental Pollution, (2005), Crop Spraying and the Health of Residents and Bystanders, (London: www.rcep.org.uk).

Sparrow, M. K. (2000), The Regulatory Craft: Controlling Risks, Solving Problems and Managing Compliance, (Washington DC: Brookings Press).

Stringer, J., and Richardson, J. (1982), 'Policy stability and policy change: industrial training 1964/82’, Public Administration Bulletin, no 39, pp. 22-39.

Waage, J..K. (1997), 'Biopesticides at the Crossroads: IPM Products or Chemical Clones?’ In 1997 BCPC Symposium Proceedings Ni.68: Microbial Insecticides: Novelty or Necessity?, pp. 11-19.

Yin, R.,K. (1989), Case Study Research: Design and Methods (London:Sage). 


\section{ENDNOTES}

\footnotetext{
${ }^{\text {I }}$ PSD was formerly an agency of Defra (Department for Environment, Food and Rural Affairs). Defra Ministers remain responsible for pesticides policy.

${ }^{\text {II }}$ There are some exceptions. See Flyvjerg (2006) for a very helpful analysis.

III This approach to defining biopesticides is taken from 'Biopesticides: The Way Ahead', a briefing article for a Conference held at the Royal Agricultural Society of England, Stoneleigh Park, Warwickshire, in October 2006.

IV Epistemic communities are knowledge-based communities with an authoritative claim to policyrelevant knowledge within their domain of expertise.

${ }^{\mathrm{V}}$ Email correspondence with Lisa Moakes, Biopesticides Champion, $26^{\text {th }}$ April 2007.

${ }^{\mathrm{VI}}$ The PSD Annual Report (2007) refers to 4 products having gone through the schemes. The figure quoted in the text is an updated figure, confirmed by Lisa Moakes via email, 30 ${ }^{\text {th }}$ October 2007.

VII This is the subject of a PhD thesis, see http://www.city.ac.uk/hmfp/dps/David\%20Buffin\%20PhD.pdf

${ }^{\mathrm{VIII}}$ This was a Conference on Biopesticides and IPM.

${ }^{\text {IX }}$ Workshop at PSD attended by Wyn Grant, $4^{\text {th }}$ April 2007, at which he gave a lecture on 'The Regulatory Challenge'.

${ }^{\mathrm{x}}$ The Government's Sustainable Development website can be found at http://www.sustainabledevelopment.gov.uk/what/index.htm. It defines sustainable development as "'development which meets the needs of the present without compromising the ability of future generations to meet their own needs'

XI This was held at Warwick HRI - more information at http://www2.warwick.ac.uk/fac/soc/pais/biopesticides/events

${ }^{\mathrm{XII}}$ Held in Brussels, the Conference was entitled 'Balanced Regulation for Biological Plant Protection'. ${ }^{\text {XIII }}$ At the PSD workshop, $4^{\text {th }}$ April 2007 it was suggested that Defra may prefer some distance as pesticides are seen as 'nasty'.

${ }_{\mathrm{XIV}}$ Regulation of Environmental Biological Control Agents

$\mathrm{XV}$ The agency's approval costs are financed through the payment of fees for evaluation of specific pesticide approvals applications and an annual levy which is based on annual turnover of approved pesticide products and is charged to the chemical industry.

${ }^{\mathrm{XVI}} \mathrm{REACH}$ was adopted in Dec 2006 by the Council of Environment Ministers and aims to improve the protection of the environment and human health through earlier and better identification of the properties of chemical substances.
} 